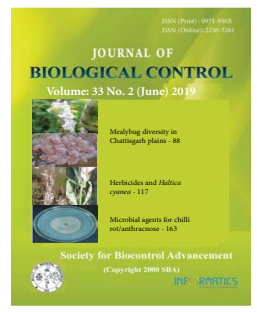

Research Article

\title{
Evaluation of volumes of Ceratitis capitata larvae in exposure devices to Diachasmimorpha longicaudata in mass rearing conditions in Costa Rica
}

\author{
ROSSY MORERA-MONTOYA ${ }^{\mathbf{1}^{*}}$, HELGA BLANCO-METZLER ${ }^{2}$ and MARÍA ISABEL GONZÁLEZ-LUTZ ${ }^{3}$ \\ ${ }^{1}$ Master of Science in Agricultural Sciences and Natural Resources with Emphasis on Crop Protection, University of Costa \\ Rica. Cacao, Alajuela - 20112, Costa Rica \\ ${ }^{2}$ Protection Research Centre, University of Costa Rica, Sede Rodrigo Facio. San Pedro, Montes de Oca. San José - 11801, \\ Costa Rica \\ ${ }^{3}$ School of Statistics, University of Costa Rica.San José - 11801, Costa Rica \\ "Corresponding author E-mail: rossymorera@gmail.com
}

\begin{abstract}
Five volumes $\left(60 \mathrm{cc}, 70 \mathrm{cc}, 80 \mathrm{cc}, 90 \mathrm{cc}\right.$ and $100 \mathrm{cc}$ ) of $\mathrm{L}_{3}$ of Ceratitis capitata in exposure devices to the parasitoid Diachasmimorpha longicaudata were evaluated in mass rearing conditions with the objective of finding the optimal quantity of host larvae to obtain the best parasite quality parameters. The variables like parasitism, sexual proportion and fertility were analyzed with ANOVA and compared with Tukey's range test. Significant differences were found for treatment in the variable parasitism $(\rho=0.0244)$, showing that the treatments of $60 \mathrm{cc}$ and $70 \mathrm{cc}$ obtained the highest number of parasitized larvae. The variables like sex ratio and fertility did not show any difference between treatments, but for fecundity there were variations for days 5 and $3(\rho<0.0001)$. The flight ability, male and female mortality and fertility variables were analyzed with the model of logistic regression analysis with autocorrelation correction (response variable is binomial), for which treatment effects were found only in the variable mortality of males for the treatment $70 \mathrm{cc}$. According to these results, the volume of $70 \mathrm{cc}$ would be the promissory treatment for industrial production in order to obtain greater parasitism and a longer life of males.
\end{abstract}

KEY WORDS: Ceratitis capitata, Diaschamimorpha longicaudata, exposure device, mass rearing, parasitism, quality control

(Article chronicle: Received: 12-11-2018 ; Revised: 15-03-2019; Accepted: 22-04-2019)

\section{INTRODUCTION}

In 1955, a specimen of the Mediterranean fruit fly (Ceratitis capitata) was detected for the first time in Costa Rica (Padilla-Monge, 2012). Initially chemical control was used to prevent the pest from spreading to the rest of the country, but that same year it was decided to import Diachasmimorpha longicaudata (Biosteres longicaudatus) (Ashmead) (Hymenoptera: Braconidae), Psyttalia concolor (Szépligeti) (Hymenoptera: Braconidae) and Pachycrepoideus vindemmiae (Rondani) (Hymenoptera: Pteromalidae) from Hawaii and Italy with the help of the Ministry of Livestock and the United States Department of Agriculture (USDA) (Jirón and Mexzón, 1989; Ovruski et al., 2000).

Introduced parasitoids were reared massively in Hawaii, where artificial techniques were available to mass rear fruit fly parasitoids (Marucci and Clancy, 1950; Chong, 1961). Therefore, from Hawaii, parasitoids such as Aganaspis daci (Weld) (Hymenoptera: Eucoilidae), Aceratoneuromyia indica (Silvestri) (Hymenoptera: Eulophidae), Fopius arisanus (Sonan) (Hymenoptera: Braconidae), Fopius vandenboschi
(Fullaway) (Hymenoptera: Braconidae), D. longicaudata, Diachasmimorpha tryoni (Cameron) (Hymenoptera: Braconidae), Dirhinus giffardii (Silvestri) (Hymenoptera: Chalcididae) and Psyttalia incisi (Silvestri) (Hymenoptera: Braconidae) were successfully imported to Costa Rica. P. concolor was also imported from Italy. Five species were established in laboratory colonies for mass release in Costa Rica, and in the early 1960s, Costa Rica provided these species for mass release to 11 countries of Americas (Ovruski et al., 2000).

Despite the wide range of fruit fly parasitoids that were produced at that time, the parasitoid that was successfully raised massively was $D$. longicaudata, thanks to the methodology created by Greany et al. (1976) for D. tryoni. In addition, due to the efficient adaptation to the conditions of mass rearing that $D$. longicaudata presented around the world, it was decided to undertake a biological control project in the National Fruit Fly Program, to strengthen the Integrated Pest Management plans that were developed in different crops of the country (Padilla-Monge, 2012). 
Diachasmimorpha longicaudata is a solitary parasitoid, endoparasitoid of the third larval stage in tephritids (Van Nieuwenhove and Ovruski, 2011), native to the IndoAustralian region (Montoya et al., 2000). The females are attracted by volatile compounds that make it easier to find the larva, in addition, they are guided by the vibrations that the larva of the third stage generates, product of its high mobility (Carrasco et al., 2005).

In Mexico, they have taken the methodologies of Greany et al., (1976) and Wong and Ramadan (1992) and adapted them to their conditions (Cancino and Montoya, 2006; Cancino et al., 2010) to produce parasitoids with greater adaptability. Among critical aspects in mass rearing, we could find exposure devices, the exposure time, breeding cages, development conditions, maintenance of the colony of adult parasitoids and the use of irradiation to avoid the emergence of the hosts (Cancino et al., 2010).

The exposure devices are fundamental in a mass rearing process, since it corresponds to an artificial site where the host is placed, which must be accepted by the parasitoid to which it is to be exposed and the design should facilitate its parasitation (Cancino et al., 2010). In the case of the massive production of $D$. longicaudata in $C$. capitata, flat hoops with flexible porous fabrics have been used that adapt perfectly to the exposure device, to prevent the larvae from entering places where the parasitoid cannot reach (Wong et al., 1991; Cancino et al., 2006b). The larva was placed with or without diet within these exposure devices. Normally, exposure device with a thickness less than or equal to $0.5 \mathrm{~cm}$ were used, where the parasitoid can find the host due to the vibrations that the larva of the third instar produces with its violent movement (Lawrence, 1981). According to the species of parasitoid, exposure times vary, and in the case of fruit fly parasitoids, it is very common to find superparasitism, which in intermediate levels can be positive because of the high generation of females, but when the insect is highly parasitized it tends to produce more males, so the exposure times must be constantly evaluated, to avoid this behaviour (Cancino et al., 2010).

The shape of the exposure device determines the shape of the cage, where the larvae will be exposed (Cancino et al., 2010). The cages and population density of adult parasitoids is sparsely studied and factors such as luminosity and ventilation should be considered for adequate parasitisation (Cancino et $a l .$, 2010). The quality of the host is very important. Since most parasitoids of fruit flies are koinobionts, they require a well-nourished host, where the larva of the parasitoid can develop properly (Cancino et al., 2010).
The colony management is a critical factor in mass production, since it must guarantee an adequate amount of light that sexually activates the parasitoids, and that there is enough ventilation so that the environment is not saturated with pheromone, and the males can copulate the females easily (Cancino et al., 2010). The use of irradiation occurs because the hosts are not $100 \%$ parasitized, so it is irradiated to prevent larvae that have not been parasitized from emerging, contaminating the release site. For this, irradiating equipment is required, gamma ray irradiators are commonly used (Cancino et al., 2002, Viscarret et al., 2012), but X-rays are used in Costa Rica, since they handle low volumes of production in comparison with Mexico, and the purchase of this type of equipment is much simpler. However, when the equipment is damaged, the spare parts are very expensive and specialized technicians that can repair the equipment in the country is scarce. For this reason, it is often necessary to turn to host and parasitoid separation using special cages that take advantage of the days of difference between the hostparasitoid emergence times.

Currently, Mexico has established the world's largest production of this parasitoid (Cancino et al., 2010), and has supported the PNMF in Costa Rica in terms of knowledge generation. However, differences in technologies and resources have meant that Costa Rica uses different methodologies than those of Mexico, which must be evaluated and adapted to their own conditions. Among the most important differences is the exposure device, since Mexico uses cassette-type oviposition devices, rectangular, with anti-aphid mesh and is inserted through a slot in the vertical cages (Cancino et al., 2010). In Costa Rica, the exhibition units are round and flexible with fabric adapted to the ring, and the used cages are horizontal, in which the exposure device is placed on top of the cage. These differences generate the need to fine-tune the production process of parasitoids from the industrial point of view. When parasitoids are massively produced, it is necessary to evaluate the quality of the host to ensure good results in the parasitoids that are later released to the field (Cancino et al., 2006c). This quality control must be carried out during two very important steps of the process: during the production of the host which will determine the conditions in which the parasitoid is going to develop, and finished product, which corresponds to the parasitoid produced to be released in the field (Cancino et al., 2006c). These evaluations are carried out constantly and are based on standards established by laboratory tests (Cancino et al., 2006c). The used host quality parameters are: egg viability, average weight of the larva, percentage of pupation, mortality at 72 hours and pupal weight (Cancino et al., 2006c). To control the quality of the final product, the quality parameters are adult emergence, survival, fecundity, flight ability, search behaviour by olfactometry and fecundity of parasitoids 
(Cancino et al., 2006c). The objective of this investigation was to determine the necessary larva volume of the third instar of C. capitata in exposure devices for mass rearing of $D$. longicaudata, which would increase the percentage of parasitism and also the quality of the parasitoids produced for field release. Quality parameters such as parasitism, sexual proportion, females and male's survival with food and water, fecundity and flight ability were compared for this purpose.

\section{MATERIALS AND METHODS}

The work was carried out in the facilities of the National Fruit Fly Program (PNMF), the State Phytosanitary Service (SFE) of the Ministry of Agriculture and Livestock, in Pavas, San José, Costa Rica.

\section{Colony of adult parasitoids}

$1000 \mathrm{cc}$ of parasitized pupae was placed for emergence in a plastic tray $(32 \times 22 \times 3 \mathrm{~cm})$ covered with Kraft paper. In each stainless-steel cage which was of the dimensions of $71 \times 47 \times 38 \mathrm{~cm}$ and covered with anti-aphid mesh, a tray with parasitized pupa was placed. Inside each cage were placed two $90 \mathrm{~mm}$ plastic Petri dishes, one with a sponge and water, so that the parasitoids could drink water and not get trapped, and another with a mixture of $17 \mathrm{~g}$ of honey and $1 \mathrm{~g}$ of toilet paper, so that they can feed themselves ad libitum.

The room for parasitoid emergence was maintained at a temperature of $26-28^{\circ} \mathrm{C}$, a relative humidity of $60-70 \%$ and 12 light hours. The adult parasitoids were maintained at a temperature of $23-25^{\circ} \mathrm{C}$, and a relative humidity of $70-80 \%$. The parasitized pupae were maintained at temperatures of $24-26^{\circ} \mathrm{C}$ and a relative humidity between $70 \%$ and $80 \%$.

\section{Colony of Ceratitis capitata}

Adults of C. capitata were maintained at $25-27^{\circ} \mathrm{C}$, at a relative humidity of $60-70 \%$. The larvae in the diet were maintained at a temperature of $29-31^{\circ} \mathrm{C}$ and a relative humidity of $70-80 \%$. Oviposition was stimulated with 8 light hours with fluorescent lamps. The cages have blanket-like fabric on each side, where the females oviposit. The adults were kept ad libitum with a food supplement based on Torula powder (50\%) and sugar (50\%), and wet sponges were placed on top of the cages so that adults could consume water.

\section{Mass rearing procedure}

When the egg was collected from the fruit fly colonies, it was placed in water with a fish tank pump, in order to simulate the oxygenation process that the egg undergoes inside the fruit. For each species a specific number of hours of bubbling is required. In the case of the eggs of Ceratitis capitata, they were bubbled for a period of 24 hours. After this, the eggs were placed on diets based on corn dough, imported ground corn cobs, sugar, protein Torula, citric acid, sodium benzoate and Guar gum, in different proportions according to the needs of each species. For $4 \mathrm{cc}$ of $C$. capitata egg, a diet based on $1 \mathrm{~kg}$ of corn powder, $0.514 \mathrm{~g}$ of corn flour, $619 \mathrm{~g}$ of Torula yeast, $1.050 \mathrm{~kg}$ of refined white sugar, $10 \mathrm{~g}$ of guar gum, $20 \mathrm{~g}$ of sodium benzoate, $25 \mathrm{~g}$ of citric acid and $4 \mathrm{~L}$ of water was used.

\section{Parasitisation procedure Larval exposure}

The hosts were separated from the diets by washing them with water and metal strainers which were of $25 \mathrm{~cm}$ in diameter with $30 \times 30$ stainless steel mesh. Subsequently, $50 \mathrm{cc}$ of ground corn cobs were added for each litre of larvae that was recovered and then, the different volumes of larvae, L3 of Ceratitis capitata were introduced: 60, 70, 80, 90 and $100 \mathrm{cc}$ of larvae (with four repetitions of each treatment) in polyethylene rings 1.2 $\mathrm{cm}$ thick, $11.5 \mathrm{~cm}$ in diameter, covered by a lycra knitted fabric with the ability to stretch adapted to the ring. This device restricted the larvae to remain between the fabric and the hoop. The entrance of the fabric bag was tied with two cords that worked to close tightly the structure and prevent the escape of the larvae. Each of these rings was placed on top of a $71 \times 47 \times 38 \mathrm{~cm}$ cage, covered with anti-aphid mesh (50 mesh size), where the adult females and males of Diachasmimorpha longicaudata were found 7-8 days after emergence. In this phase, the larvae were kept at a temperature of $22-24^{\circ} \mathrm{C}$, a relative humidity of $60-70 \%$ and white light was used. The time of exposure of the larva to parasitisation was 4 hours. The larva corresponding to each treatment was placed in transparent plastic trays of $32 \times 22 \times 3 \mathrm{~cm}$, duly labelled.

\section{Post-exposure period and development of parasitoids}

A manual mixing of ground corn cobs was performed with the newly exposed larvae. The trays were placed in a development room at $26{ }^{\circ} \mathrm{C}, 50-70 \%$ humidity and in darkness. Seven days after the exposure, the pupae were placed in a special cage for five more days, to separate the fruitflies from the parasitoids. As the life cycle of $C$. capitata is 7 days shorter than that of the parasitoid D. longicaudata, it was left in the cage until all the adults of the host died, and later a fan was used to eliminate the emerged pupae and separate the parasitized pupae. The quality parameters evaluated were performed using a methodology similar to those used in Moscafrut SAAGARPA-IICA, Mexico (Cancino et al., 2006a).

\section{Quality of the parasitoid}

Among the quality parameters of Diachasmimorpha longicaudata, the following were evaluated. 


\section{Percentage of parasitism}

Once the exposure rings were removed from the cages, the larvae of each treatment were placed in plastic trays of $32 \times 22 \times 3 \mathrm{~cm}$. The next day, 4 samples of 100 pupae were taken at random from the exposed batch, in labelled petri dishes. When the parasitoids of each treatment have emerged, they were expected to die to account for them. The number of emerged flies and the proportion of females and males were counted.

\section{Sexual proportion}

Once the flies have emerged, the parasitized pupae were separated from the emergency debris of the flies and 4 samples of 100 pupae were taken per petri dish. Once the parasitoids have emerged and died, the number of females, males and empty pupae present in the sample were counted.

\section{Flying ability}

In buckets of $20 \mathrm{~L}$ capacity with the interior painted with matte black water paint, a black PVC tube was placed (10 cm diameter and $10 \mathrm{~cm}$ height). The inner walls of the tube were soaked with fine corn starch without colour or odour, in order to prevent the parasitoids from escaping. A petri dish with 100 pupae was placed inside the tube and the bucket was covered with tergal saturated with colourless and odourless glue, in order to prevent the flying parasitoids from entering other units, interfering thereof in the counting. Five days after emergence, the parasitoids that were found inside the tube were considered as those with no flight capacity. Four repetitions were made (Poncio et al., 2016). The number of parasitoids that failed to fly out of the tube and the empty pupae were counted, and thus the percentage of flying parasitoids was obtained considering only those that have emerged.

\section{Mortality and fertility without stress}

The methodology proposed by Poncio et al. (2016) was used to measure the fecundity and mortality of the parasitoids. 25 males and 50 females were placed in cages of $50 \mathrm{~cm} \times 60 \mathrm{~cm} \times 39 \mathrm{~cm}$, of white colour, with anti-aphid mesh (50 mesh), a petri dish with water, and another one with the mixture of honey. The parasitoids were selected from the batch of emerged parasitoids in each treatment; 3 days after the females have emerged. Once in the cages, a petri dish covered with white tergal was adhered with adhesive tape, to prevent the larvae of $C$. capitata from leaving. $5 \mathrm{cc}$ of larvae and ground corn cobs were added to each Petri dish for six days, to observe the fertility behaviour of the females obtained in each treatment from day 5 to day 10. Each petri dish was placed vertically to cage wall to encourage the larvae to accumulate and the parasitoid could easily detect it. Each treatment had four repetitions, each in a different cage.
At each repetition, an exposure ring was incorporated for 2 hours. At the end of the exposure time, the larva was taken, $10 \mathrm{~g}$ of ground corn cobs was added, it was sealed and labelled. Once the flies and parasitoids have emerged, males, females, total number of emerged flies and empty pupae were counted. The number of females and males that died in each repetition was counted for a period of 14 days.

\section{Statistical analysis}

Three different batches of host and parasitoid production were analyzed in order to reduce variability between production batches over time. Each treatment consisted of four repetitions. The experimental unit for parasitism, sexual proportion and fecundity corresponded to the petri dishes and these were evaluated by means of ANOVA. The multiple means comparisons were made according to the Tukey method $(\rho=0.05)$ to observe significant differences between treatments.

The variables like flight ability and mortality of males and females were analyzed with the model logistic regression analysis with correction for autocorrelation (response variable is binomial) and were compared through the maximum likelihood analysis.

\section{RESULTS AND DISCUSSION}

The variable sex ratio $(\rho=0.0757)$ showed no differences between treatments (Table 1). Also, the fertility variable did not present treatment differences $(\rho=0.4437)$, but for the days $(\rho<0.0001)$, the difference was specifically presented on days 5 and 3 , with day 5 being the one with the highest fecundity and on day 3, the one with the least fecundity (Fig. 1). For the variable parasitism, the treatment effect presented a probability of 0.0244 , showing that the treatments of $60 \mathrm{cc}$ and $70 \mathrm{cc}$ obtained the highest number of parasitized larvae.

According to the logistic regression analysis with correction for autocorrelation, the variables like flight ability and mortality of females did not present a treatment effect: $\rho=0.1014$ and $\rho=0.5484$, respectively. However, for male mortality, there was a treatment effect (Table 2). The model adjusted for the variable of mortality of males was the following: lny $=3.3381-0.2182 *$ batch $2-3.0882 *$ batch $3-0.8678 * 60$ cc- $0.9434 * 70$ cc- $2.1144 * 80$ cc- $0.9146 * 90$ cc

Biological control has followed the trend of using biological control agents well adapted to mass rearing conditions, which allows maintaining constant release volumes, but with this comes the challenge of maintaining efficient organisms in the field, which can easily adapt to different environmental conditions, and that are capable of 
Table 1. Parasitism, sexual proportion and fecundity evaluated for Diachasmimorpha longicaudata on third instar larvae of Ceratitis capitata

\begin{tabular}{|c|cc|cc|cc|}
\hline $\begin{array}{c}\text { Treatment } \\
\text { (cc of larvae) }\end{array}$ & Parasitism (\%) & $\begin{array}{c}\text { Sexual } \\
\text { proportion } \\
\text { (females/ } \\
\text { males) }\end{array}$ & Fecundity (\%) \\
\hline $60 \mathrm{cc}$ & $65 \%$ & $\mathrm{~A}$ & 1.23 & $\mathrm{~A}$ & $36 \%$ & $\mathrm{~A}$ \\
\hline $70 \mathrm{cc}$ & $65 \%$ & $\mathrm{~A}$ & 1.02 & $\mathrm{~A}$ & $36 \%$ & $\mathrm{~A}$ \\
\hline $80 \mathrm{cc}$ & $63 \%$ & $\mathrm{AB}$ & 0.84 & $\mathrm{~A}$ & $35 \%$ & $\mathrm{~A}$ \\
\hline $90 \mathrm{cc}$ & $60 \%$ & $\mathrm{AB}$ & 0.62 & $\mathrm{~A}$ & $42 \%$ & $\mathrm{~A}$ \\
\hline $100 \mathrm{cc}$ & $53 \%$ & $\mathrm{~B}$ & 0.79 & $\mathrm{~A}$ & $36 \%$ & $\mathrm{~A}$ \\
\hline
\end{tabular}

Different letters indicate significant differences based on Tukey's analysis $(\rho=0.05)$

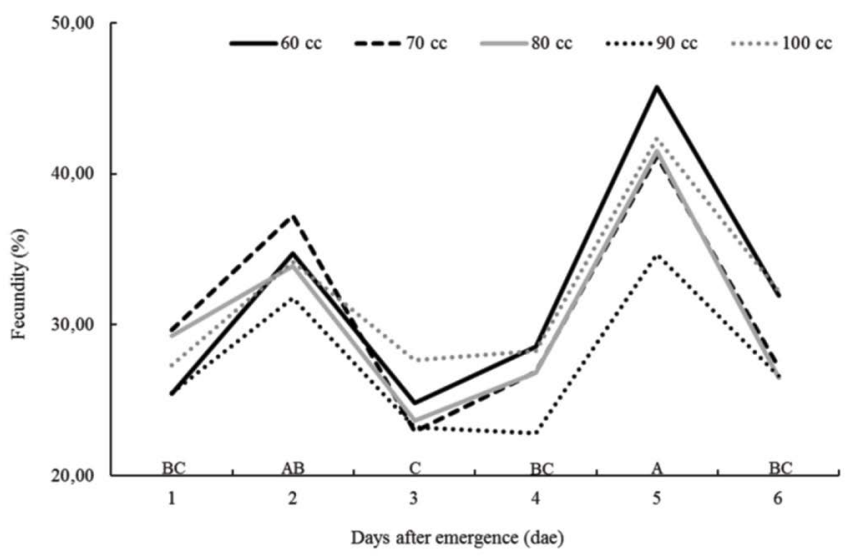

Fig. 1. Fecundity of the emerged females in each treatment. Note: Different letters indicate significant differences according to Tukey $(\rho=0.05)$.

Table 2. Results of the comparisons between treatments and the odds ratio for each comparison with its respective significance for the variable mortality of males

\begin{tabular}{|l|c|c|}
\hline $\begin{array}{c}\text { Comparison between } \\
\text { treatments }\end{array}$ & Odds Ratio & Significance \\
\hline $60 \mathrm{cc}$ vs. $70 \mathrm{cc}$ & 1.07853 & 0.99991 \\
\hline $60 \mathrm{cc}$ vs. $80 \mathrm{cc}$ & 0.05068 & 0.00000 \\
\hline $60 \mathrm{cc}$ vs. $90 \mathrm{cc}$ & 1.04791 & 0.99999 \\
\hline $60 \mathrm{cc}$ vs. $100 \mathrm{cc}$ & 0.41987 & 0.00000 \\
\hline $70 \mathrm{cc}$ vs. $80 \mathrm{cc}$ & 0.04699 & 0.00000 \\
\hline $70 \mathrm{cc}$ vs. $90 \mathrm{cc}$ & 0.97161 & 0.00000 \\
\hline $70 \mathrm{cc}$ vs. $100 \mathrm{cc}$ & 0.38930 & 0.00000 \\
\hline $80 \mathrm{cc}$ vs. $90 \mathrm{cc}$ & 20.67655 & 0.00000 \\
\hline $80 \mathrm{cc}$ vs. $100 \mathrm{cc}$ & 8.28461 & 0.00170 \\
\hline $90 \mathrm{cc}$ vs. $100 \mathrm{cc}$ & 0.40068 & 0.00000 \\
\hline
\end{tabular}

attacking the plague or target disease. For this reason, in the mass rearing of biocontrol agents, quality controls are being used to guarantee the good performance of these organisms in the field (Sorensen et al., 2012).

Aspects such as fecundity and sexual proportion are indicators of quality for parasitoids (Goncalves et al., 2005), therefore a greater number of females assures that there is greater oviposition in the field and thus efficient management of the pest. The ability to fly has also been used as a parameter to measure the ability of the parasitoid to reach its host (Cancino et al., 2006a). In this study, no differences were found between treatments for the variables like sex ratio and fertility, but for parasitism there were differences, the highest percentages of parasitism were those found in $60 \mathrm{cc}$ and $70 \mathrm{cc}$ treatments $(65 \%$, Table 1$)$, these percentages were comparable with those obtained by Sánchez et al. (2016) in the field, which were also between $16 \%$ and $75 \%$ on Ceratitis capitata. It is important to note that the fertility variable showed significant differences between days (Fig 1). It was observed that the fecundity was least on day 3 and it was highest on day 5. Literature does not show a definite pattern of fertility; however, Liu et al. (2012) opined that the effect of temperature on this variable is essential and attributed arange of temperature from $24^{\circ}$ to $27^{\circ} \mathrm{C}$ as preferred by Diachasmimorpha longicaudata in Bractocera dorsalis (Hendel) (Diptera: Tephritidae), under laboratory conditions.

There are many factors that can intervene in the mortality of both females and males. Paranhos et al. (2008) found that, in cages with a higher proportion of females, mortality increased, in ratios of 5:1 and it was also observed that productivity and fertility were lowered. However, in the case of this investigation, the cages where mortality and fertility were evaluated had a proportion of females of $2: 1$. The mortality variable only presented a treatment effect for the males (Table 2) and among the comparisons made, it was observed that the volume of $70 \mathrm{cc}$ was the one that managed to lengthen the life of the male. This finding suggests that, by lengthening the life of the males, the females can be copulated for a longer time since the females emerge 2-3 days after the males (Harbi et al., 2016), therefore, the females could count on males for more time to copulate.

Some factors that could intervene in the results of this research are the age of the rearing of both parasitoids and the host, C. capitata. However, recent studies have determined that in parasitoids of the family Platygastridae (Hymenoptera), there is no evidence of negative effects on breeding rearing established in France for more than 9 years (Quaglietti et al., 2017). DeClercq et al. (1998) 
ROSSY MORERA-MONTOYA et al.

found that in the mass rearing of Podisus maculiventris, a predatory hemipteran, there was no problem of inbreeding depression upto 15 generations, but upon reaching the $30^{\text {th }}$ generation, there was lowering of fertility. The problem of inbreeding depression that occurs in the rearing will vary depending on the species. The deterioration of the breeding is attributed to environmental rather than genetic factors (DeClercq et al., 1998).The density of individuals per cage is another factor that could be interfering in the quality of parasitoids obtained in the mass rearing process., MedinaPereyra et al. (2016) found that the sex ratio and density of adults increase the number of egg positions of Diatraea saccharalis in conditions of mass rearing. Therefore, it is necessary to measure the density of females for oviposition that are required to increase parasitism and improve the other quality variables. Host exposure times to parasitoids play a very important role. In some investigations, it has been studied that the emergence of parasitoids is greater at times of 30 minutes of exposure, in different proportions of host: parasitoid of 2: 1, 4: 1, 6: 1, 8: 1 and10: 1 (Van Nieuwenhove et al., 2012). With this information, it could be thought that the exposure times used in the PNMF Plant are very long (4 hours), which leads to greater progeny mortality and lower super parasitism (Van Nieuwenhove et al., 2012; Suarez et $a l ., 2012)$. Unfortunately, super parasitism was not studied in this research, nor the exposure times, but it must be evaluated.

When analyzing the variables that responded to the different treatments, parasitism and mortality respond to the treatment of $70 \mathrm{cc}$ of larva of the third instar. Therefore, it is recommended to use this volume of larva to expose the parasitoid, $D$. longicaudata, with the objective of improving the quality of the progeny that is released in the field. Mass production requires a thorough knowledge of the biology of both the host and the parasitoid, in order to create the ideal conditions that enhance the performance of the natural enemy and, at the same time, lower production costs. This challenge makes necessary the constant study of different variables and factors that may be linked to a better quality of the production of biocontrol agents. This study was able to demonstrate that small changes in the system of mass production of parasitoids influence biological and ecological factors of the parasitoids that are released in the field.

\section{ACKNOWLEDGEMENTS}

This research was possible because of the support of the National Fly Fruit Program (PNMF), for providing material and facilities to carry out the project. Special thanks to the University of Costa Rica for financing the possibility of attending the Congress and the ICBC organizers for giving us the opportunity to communicate the results of this research.

\section{REFERENCES}

Cancino J, Ruiz L, Gómez Y, Toledo J. 2002. Irradiación de larvas de Anastrepha ludens (Loew) (Diptera: Tephritidae) para inhibir la emergencia de moscas de la cría del parasitoide Diachasmimorpha longicaudata (Ashmead) (Hymenoptera: Braconidae). Folia Entomol Mexicana 41: 195-208.

Cancino J, López P, Villalobos P, Hipólito P, Quintero J, Mattiacci L. 2006a. Control de calidad en la cría masiva de Diachasmimorpha longicaudata (Hymenoptera: Braconidae). Fundamentos y Procedimientos. Secretaría de Agricultura, Ganadería, Desarrollo Rural, Pesca y Alimentación (SAGARPA), Dirección General de Sanidad Vegetal (Senasica). México. PMCid:PMC1685843

Cancino J, Ruiz L, López P, Moreno FM. 2006b. Cría masiva de parasitoides. In: Montoya P, Toledo J, Hernández E (Eds.). Moscas de la Fruta: Fundamentos $y$. Procedimientos para su Manejo. México, D.F. PMCid:PMC1685843

Cancino J, Montoya P. 2006. Advances and Perspectives in the Mass Rearing of Fruit Fly Parasitoids in Mexico. In: Proceedings 7th International Symposium on Fruit Flies of Economic Importance 10-15 September 2006, Salvador, Brazil. PMCid:PMC1685843

Cancino J, López P, Villalobos P, Hipólito P, Quintero J, Mattiaci L. 2006c. Control de calidad en la cría masiva de Diachasmimorpha longicaudata (Hymenoptera: Braconidae). Fundamentos Y Procedimientos. Senasica, México. PMCid:PMC1685843

Cancino J, Ruiz L, López P, Moreno F. 2010. Cría masiva de parasitoides. In: P Toledo J, Hernández E, (Eds.). Moscas de la Fruta: Fundamentos y Procedimientos para su Manejo. México, D.F. PMCid:PMC2921116

Carrasco M, Montoya P, Cruz-López L, Rojas J. 2005. Response of the fruit fly parasitoid Diachasmimorpha longicaudata (Hymenoptera: Braconidae) to mango fruit volatiles. Environ Ent. 34: 576-583. https://doi. org/10.1603/0046-225X-34.3.576

Chong M. 1961. Production methods fruit fly parasites. Proc Hawaiian Entomol Soc. 18: 61-63.

Declerq P, Vandewalle M, Tirry L. 1998. Impact of inbreeding on performance of the predator Podisus maculiventris. BioControl 43: 299-310. https://doi. org/10.1023/A:1009961921817 
García J, Iannacone J. 2011. Viabilidad de huevos y modelo de jaula para la cría artificial masiva de Anastrepha fraterculus (Diptera: Tephritidae). Revista de la Soc Entomol Argentina 70: 267-276.

Greany PD, Ahsley TR, Baranowski RM, Chambers DL. 1976. Rearing and life studies of Biosteres (=Opius) longicaudatus a parasite of the Caribbean fruit fly Anastrephas uspensa. Ann Entomol Soc America 70: 319-321. https://doi.org/10.1093/aesa/70.3.319

Gonçalves C, Amaro F, Figueiredo E, Godinho M, Mexia A. 2005. Productivity and quality aspects concerning the laboratory rearing of Trichogramma spp. (Hym.: Trichogrammatidae) and its factitious host, Ephestia kuehniella Zeller (Lep.: Pyralidae). Bol San Veg Plagas 31: 21-25.

Harbi A, Abbes K, Chermiti B, Martins D, Hafsi A, SabaterMu-oz B, Beitia F. 2016. Life history parameters of Diachasmimorpha longicaudata on Ceratitis capitata under laboratory conditions: Implications for mass rearing and biological control. Tunisian J Pl Prot. 11: $207-217$.

Jirón L, Mexzón R. 1989. Parasitoid hymenopterans of Costa Rica: geographical distribution of the species associated with fruit flies (Diptera: Tephritidae). Entomophaga 34: 53-60. https://doi.org/10.1007/BF02372587

Liu CY, Chen KW, Zeng L. 2012. Effects of temperature on the development and fecundity of Diachasmimorpha longicaudata (Ashmead). J App Ecol. 23: 3051-3056.

Marucci PE, Clancy DW. 1950. The artificial culture of fruit flies and their parasitoids. Proc Hawaiian Entomol Soc. 14: 103-106.

Medina-Pereyra P, OrdanoM, Reguilón C, Salvatore A, Acosta C, Risso L. 2016. El papel de la densidad y la proporción sexual de adultos en la fecundidad de Diatraea saccharalis (Lepidoptera: Crambidae) en jaulas de cría masiva. Rev Soc Entomol Argentina 75: 165-171.

Montoya P, Liedo P, Benrey B, Cancino J, Barrera J, Sivinski J, Aluja M. 2000. Biological control of Anastrepha spp. (Diptera: Tephritidae) in mango orchards through augmentative releases of Diachasmimorpha longicaudata (Ashmead) (Hymenoptera: Braconidae). Biol Control. 18: 216-224. https://doi.org/10.1006/ bcon. 2000.0819

Ovruski S, Aluja M, Sivinski J, Wharton R. 2000. Hymenopteran parasitoids on fruit-infesting Tephritidae
(Diptera) in Latin America and the southern United States: Diversity, distribution, taxonomic status and their use in fruit fly biological control. Integrated Pest Manag Rev. 5: 81-107. https://doi.org/10.1023/A:1009652431251

Padilla-Monge, M. 2012. Servicio Fitosanitario del Estado, nuestra huella en el tiempo. MAG/SFE. San José, C.R.

Paranhos B, Costa M, Ovruski S, Alves R, Blummer L, Walder J. 2008. Offspring in response to parental female densities in the fruit fly parasitoid Diachasmimorpha longicaudata (Hymenoptera: Braconidae: Opiinae). Fla Entomol. 91: 628-635.

Poncio S, Nunes AM, Gonçalves RS, Lisboa H, ManicaBerto R, Garcia MS, Nava DE. 2016. Biology of Doryctobracon brasiliensis at different temperatures: development of life table and determining thermal requirements. J Appl Ent. 140: 775-785. https://doi. org/10.1111/jen. 12308

Quaglietti B, Tamisier L, Groussier G, Fleisch A, Le Goff I, Ris N, Kreiter P, Fauvergue X, Malausa T. 2017. No inbreeding depression in laboratory-reared individuals of the parasitoid wasp Allotropa burrelli. Ecol Evol. 7: 964-973. https://doi.org/10.1002/ece3.2643 PMid:28168032 PMCid:PMC5288250

Sánchez G, Murúa F, Suárez L, Van Nieuwenhove G, Taret G, Pantano V, Ovruski S. 2016. Augmentative releases of Diachasmimorpha longicaudata (Hymenoptera: Braconidae) for Ceratitis capitata (Diptera: Tephritidae) control in a fruit-growing region of Argentina. Biol Control. 103: 101-107. https://doi.org/10.1016/j. biocontrol.2016.08.002

Sørensen J, Addison M, Terblanche J. 2012. Mass-rearing of insects for pest management: Challenges, synergies and advances from evolutionary physiology. Crop Prot. 38: 87-94. https://doi.org/10.1016/j.cropro.2012.03.023

Suarez L, Van Nieuwenhove G, Murua F, Bezdjian L, Schliserman P, Lara N, Escobar J, Ovruski S. 2012. Offspring production in response to host exposure times in Diachasmimorpha longicaudata (Hymenoptera: Braconidae), reared on the genetic sexing strain Vienna 8 of Ceratitis capitata (Diptera: Tephritidae). Fla Entomol. 95: 991-999. https://doi.org/10.1653/024.095.0426

Van Nieuwenhove G, Ovruski S. 2011. Influence of Anastrepha fraterculus (Diptera: Tephritidae) larval instars on the production of Diachasmimorpha longicaudata (Hymneoptera: Braconidae) progeny 
ROSSY MORERA-MONTOYA et al.

and their sex ratio. Fla Entomol. 94: 863-868. https://doi.org/10.1653/024.094.0421

Van Nieuwenhove G, Bezdjian L, Ovruski S. 2012. Effect of exposure time and ratio of hosts to female parasitoids on offspring production of Diachasmimorpha longicaudata (Hymneoptera: Braconidae) reared on Anastrepha fraterculus (Diptera: Tephritidae) larvae. Fla Entomol. 95: 99-104.https://doi.org/10.1653/024.095.0116

Viscarret M, Conte C, Zusel L, Carabajal-Paladino S, López N, Segura D, Muntaabski I, Lanzavecchia S, Cladera J. 2012. Rearing of the fruit fly parasitoid Diachasmimorpha longicaudata (Hymenoptera: Braconidae) on X-ray irradiated larvae of Ceratitis capitata (Diptera: Tephritidae). Biocontrol Sci Technol. 22: 1429-1441. https://doi.org/10.10 80/09583157.2012.731496
Wong T, Ramadan M. 1992. Mass rearing biology of larval parasitoids (Hymenoptera: Braconidae: Opinae) of tephritid flies (Diptera: Tephritidae) in Hawaii, pp/ 425-426. In: Anderson T, Leppla N. (Eds.). Advances in Insects Rearing for Research and Pest Management. Westview Press, Oxford, England.

Wong T, Ramadan M, McInnis D, Mochizuki N, Nishimoto J, Herr J. 1991. Augmentative releases of Diachasmimorpha tryoni (Hymenoptera:Braconidae) to suppress a Mediterranean fruit fly (Diptera:Tephritidae) population in Kula, Maui, Hawaii. Biol Control 1: 2-7. https://doi.org/10.1016/1049-9644(91)90094-G 